\title{
Head of NHS wants sugar content cut in breakfast cereals
}

Food manufacturers should alter the formulation of breakfast cereals to reduce their sugar content as part of on-going efforts to tackle childhood obesity and dental problems, according to the Head of the NHS in England.

Speaking to the parliamentary Health and Social Care Committee on 2 July 2018 as part of its inquiry into NHS funding, NHS England Chief Executive Simon Stevens was asked about the impact of some foods on childhood eating patterns, particularly breakfast cereals.

Stevens said: 'There are some encouraging signs. The childhood obesity strategy, mark 2, represents a significant intensification of effort compared with mark 1.'

The fact there was now a specific target to halve childhood obesity rates by 2030 was welcomed by Stevens, who said food companies needed a 'wake-up call' on the amount of sugar they currently had in their products.

'On average, children are having the equivalent of three sugar lumps at breakfast and for poorer children that is often much worse.

'That is contributing a lot to the childhood obesity epidemic so calorie labelling, traffic lighting, and changed promotional approaches in the retail sector - they have all got to play their part. But I think we are going to need to see much greater action on food reformulation over the next several years in the way that we have begun to see on sugar, sweets and beverages.

'If we don't get that, then it will be obvious that we are not going to be on track for the childhood obesity goals that the government has rightly set. There needs to be a wake-up call for food manufacturers.

'It obviously matters for the NHS, but frankly it matters to us as parents. It is our children who are inadvertently on the receiving end of what you think is a healthy breakfast cereal but often turns out not to be. We can change that and we need to.'
MPs on the committee asked Stevens if he agreed with the health priorities set out by Prime Minister Theresa May and former Health and Social Care Secretary Jeremy Hunt as part of the recently announced uplift in NHS funding by $£ 20$ billion by 2023-24.

'They are very congruent with the priorities that the NHS has been working on over the last several years,' he said, pointing to cancer outcome improvements, doing more on mental health services and care integration.

'Also, if we want to tackle inequalities and give children the best start in life, we're going to have to look at prevention, obesity, unmet needs in young people's mental health services.'

Maria Morgan, Senior Lecturer in Dental Public Health at Cardiff University School of Dentistry and Honorary Public Health Specialist (dental) at Public Health Wales, has carried out research ${ }^{1}$ into this topic published in this issue of the $B D J$.

Morgan and her colleagues found that most of the breakfast cereals they studied contained high sugar levels, and although marketers made legitimate claims about other nutritional constituents, these claims could mislead consumers into thinking the cereals were healthier than they were, while imagery of portion size - on some packets three times larger than manufacturers' recommended portion sizes - was also misleading.

'The big thing for me is the normalisation of bigger portion sizes, which is affecting childhood obesity, adult obesity and oral health', said Morgan. 'I don't like parents being hoodwinked by the imagery.

'I would welcome reformulation of these products. We need to work with the industry on this. I am also worried about food labelling post Brexit because currently food labelling conforms with EU regulations and we want it as good as if not better than what we have now?

1. Khehra R, Fairchild R M, Morgan M Z. UK children's breakfast cereals - an oral health perspective. Br Dent J 2018; DOI: 10.1038/sj.bdj.2018.531.

\section{Dentists urged to vote in forthcoming AGM over charity fund}

The BDA's Benevolent Fund - the charity caring for dentists and their families - is holding an annual general meeting (AGM) on 18 September in London.

It is inviting all BDA members - all of whom are members of the BDA Benevolent Fund - to attend and has reminded them they have voting rights for the charity.

The charity's trustees have reviewed their governing document and are proposing to bring it up to date by clarifying various matters to ensure the organisation is efficient as well as fit for the future.

The trustees are putting forward a number of recommendations and amendments to the charity's governing document, including changes to the structure of the Board and to the process of nomination and recruitment of trustees.

They are also suggesting an alteration to the Benevolent Fund's governing documents in relation to the membership as well as some administration and procedural changes.

These proposals will be put forward and voted on at the AGM at $3.30 \mathrm{pm}$ on Tuesday 18 September 2018 at 64 Wimpole Street, London.

More information about the proposed amendments or the option to RSVP to attend the AGM can be found at www.bdabenevolentfund.org/agm and those planning to attend should confirm this by 11 September 2018. 